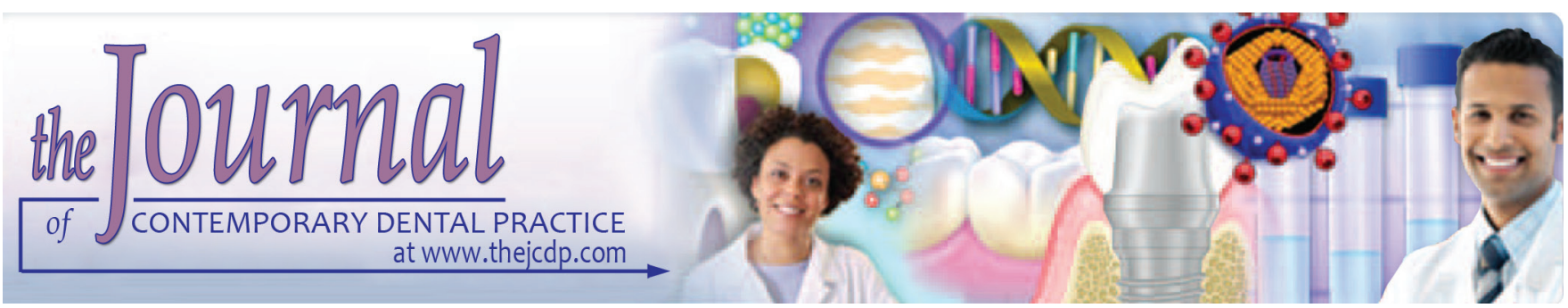

\title{
Effects of Different Temperatures and Storage Time on the Degree of Conversion and Microhardness of Resin-based Composites
}

\section{Maan M AIShaafi}

\section{ABSTRACT}

Objective: Dental materials are often made at room temperature, whereas clinically they are made in the mouth. This study evaluated the effects of temperature on the degree of conversion (DC) and Knoop microhardness (KHN).

Materials and methods: Two types of resin-based composites (RBCs) were light-cured using a light-emitting diode (LED) lightcuring unit. The resin specimens were centered on an Attenuated Total Reflectance Fourier transform infrared (FT-IR) plate heated to $23^{\circ} \mathrm{C}$ or $33^{\circ} \mathrm{C}$. The $\mathrm{DC}$ of the resin was calculated after 120 seconds, the specimens were removed, and the KHN was tested at the bottom of the specimens both immediately, after 24 hours, and after 7 days storage in distilled water in complete darkness at $37^{\circ} \mathrm{C}$. The effects of different temperatures on the $\mathrm{DC}$ and $\mathrm{KHN}$ with their storage time were compared by analysis of variance and Fisher's protected least significant difference post hoc multiple comparison tests $(p<0.05)$.

Results: Increasing the temperature had a significant and positive effect on the DC and KHN for immediate values of the RBCs. Greater conversion and hardness occurred when the curing temperature was increased from $23^{\circ} \mathrm{C}$ to $33^{\circ} \mathrm{C}$. The $\mathrm{KHN}$ increased significantly after 24 hours of storage. There was a linear relationship between $\mathrm{DC}$ and $\mathrm{KHN}\left(\mathrm{R}^{2}=0.86\right)$ within the range of DC and KHN studied.

Conclusion: The physical properties of dental materials can be expected to be better when made in the mouth than when they are made in a laboratory at room temperature.

Keywords: Bulkfill RBC, Degree of conversion, KHN, Temperatures.

Department of Restorative Dental Sciences, College of Dentistry King Saud University, Riyadh, Kingdom of Saudi Arabia

Corresponding Author: Maan M AIShaafi, Associate Professor, Department of Restorative Dental Sciences, College of Dentistry, King Saud University, Riyadh, Kingdom of Saudi Arabia, Phone: +966114677420, e-mail: malshaafi@ksu.edu.sa
How to cite this article: AIShaafi MM. Effects of Different Temperatures and Storage Time on the Degree of Conversion and Microhardness of Resin-based Composites. J Contemp Dent Pract 2016;17(3):217-223.

Source of support: This study was supported by the Deanship of Scientific Research at King Saud University and by laboratory facilities at Dalhousie University.

Conflicts of interest: None

\section{INTRODUCTION}

Over the last three decades, light-cured resin-based composites (RBCs) have become the most prevalent direct dental restorative material. ${ }^{1}$ During that time, the esthetics and both physical and mechanical properties of RBCs have improved.

The placement of a successful RBC restoration is a technique-sensitive procedure. It is important that the clinician know the features and the requirements of the $\mathrm{RBC}$ they are using to deliver an adequately cured restoration. In general, conventional light-cured RBCs are placed and light cured in 2-mm increments. ${ }^{2}$ However, manufacturers now claim that their new bulk-fill RBCs can be placed and adequately cured in 4-mm or even 6-mm increments. ${ }^{3}$

Resin-based composites can be light-cured with different types of light-curing units (LCUs). Currently, the light-emitting diode (LED) curing unit is the most commonly used in dental practice. ${ }^{4}$ Contemporary LED units often deliver high irradiance values above $2000 \mathrm{~mW} / \mathrm{cm}^{2}$ and offer a reduction in the light exposure time. This use of these high-power LCUs, together with the use of bulk-fill RBCs, can result in a significantly large time saving when placing resin-based restorations.

However, clinicians can easily miscalculate the time required for adequate light-curing of each increment of 
an $\mathrm{RBC}$, or the thickness of the RBC they are placing. This may then result in an inadequate amount of light delivered to the RBC and this will create an inadequately cured RBC. This is highly undesirable because this will lead to reduced physical and mechanical properties, increased bacterial colonization, and leaching of greater amounts of uncured monomer into the body. ${ }^{5,6}$ Conversely, excessive light-curing (especially with highpower LCUs) may overheat the soft and hard tissues, leading to possible pulpal irritation or soft-tissue burns.?

The dental literature includes reports from many laboratory experiments that have evaluated RBCs. Tests that evaluated the degree of conversion (DC) and microhardness are considered to be valid and reliable. However, most of these tests, including the ISO 4049 depth of cure standard, were conducted at room temperature, which is not the same as the temperature in the oral cavity.

It is well-known that temperature has an effect on the rate of polymerization and the $\mathrm{DC}$ of an $\mathrm{RBC}$, leading to possible alterations in its physical and mechanical properties. As the temperature increases, resin viscosity is reduced and molecular mobility increases, all leading to increase in the DC, ${ }^{8,9}$ but this effect appears to have been overlooked in many studies. The effect of testing RBCs at the same temperature found in the tooth will provide more appropriate values for the materials and help avoid either over- or undercuring of the RBC increments.

Several studies have investigated the effect of temperature on resin-curing. In a 1999 study, Lovell et al ${ }^{10}$ examined experimental resin and found an increase in the DC when increasing their tested temperatures $\left(25^{\circ} \mathrm{C}, 40^{\circ} \mathrm{C}\right.$, and $\left.55^{\circ} \mathrm{C}\right)$. Other studies evaluated different commercial resins and arrived at similar conclusions. In 2004, Trujillo et $\mathrm{al}^{11}$ found a clear relationship between temperature and resins' DC. In their study, they tested a material's DC at different temperatures $\left(23^{\circ} \mathrm{C}, 37^{\circ} \mathrm{C}, 54^{\circ} \mathrm{C}\right.$, and $70^{\circ} \mathrm{C}$ ) and concluded that the higher the temperature used, the higher the percentage of resin converted. ${ }^{11}$ Other studies showed an increase in shrinkage strain rate when temperature increased. ${ }^{12,13}$ A recent study by Watts and Alnazzawi ${ }^{14}$ confirmed the previous studies' findings, wherein there was an increase in the shrinkage stress and stress rate values of tested resins when temperature changed from $23^{\circ} \mathrm{C}$ to $37^{\circ} \mathrm{C}$. However, temperatures above $37^{\circ} \mathrm{C}$ are not found intraorally. Another recent study evaluated the effect of temperature evaluation on KHN and DC on a 2 -mm-thick RBC. Price et $\mathrm{al}^{15}$ reported a significant difference in DC $\left(47.6 \%\right.$ at $22^{\circ} \mathrm{C}$ and $57.8 \%$ at $\left.35^{\circ} \mathrm{C}\right)$ and $\mathrm{KHN}\left(21.4 \%\right.$ at $22^{\circ} \mathrm{C}$ and 31.8 at $\left.35^{\circ} \mathrm{C}\right)$.

The purpose of this study was to evaluate the effects of a simulated intraoral temperature and three measurement times on DC and KHN of two RBCs. The null hypotheses were:

- There would be no difference in DC and KHN values for RBCs when cured at room temperature compared with a simulated intraoral temperature.

- There would be no difference between immediate and postcuring readings ( 24 hours and 7 days) for the KHN values of RBCs.

- There would be no difference in DC and KHN values at the bottom of 2 and 4-mm thicknesses of RBCs.

\section{MATERIALS AND METHODS}

Two types of RBC were used, an IVA shade of Tetric EvoCeram Bulk Fill (Ivoclar-Vivadent, Amherst, NY) and a A2B shade of Filtek Supreme Ultra (3M ESPE, St Paul, $\mathrm{MN})$. All specimens were light-cured using a Valo LED LCU (Ultradent, South Jordan, UT) (Table 1) with the light tip placed directly over each specimen.

\section{Spectral Radiant Power and Radiant Exposure Received by the Specimens}

The irradiance, radiant exposure, and spectral emission from the LCU were measured by means of a 6-inch integrating sphere (Labsphere, North Sutton, NH) connected to a fiber-optic spectrometer (USB 4000; Ocean Optics, Dunedin, FL). This fiber-optic system was calibrated before the experiment using the internal reference lamp contained within the sphere. The output from the LCU was measured through a 4-mm diameter aperture placed over the entrance to the integrating sphere. This aperture matched the 4-mm diameter of the specimens, so that the sphere measured the same spectral radiant power that would be received by the specimens and not the total output emitted from the LCU. Spectrasuite v2.0.162 software (Ocean Optics, Dunedin, FL) was used for data collection and analysis. So, that the radiant exposure received by the $4-\mathrm{mm}$ diameter

Table 1: The resin-based composite resins used in the study, along with their curing light units

\begin{tabular}{lllll}
\hline Material (shade) & Abbreviation & Type & Manufacturer & Lot \# \\
\hline Filtek Supreme Ultra (2AB) & FS & Conventional & 3M ESPE, St Paul, MN, USA & N553090 \\
Tetric EvoCeram Bulk Fill (IVA) & TBF 2 or 4 mm & Bulk Fill & Ivoclar Vivadent, Amherst, NY, USA & R08233 \\
Valo & & LED & Ultradent, South Lake, UT, USA & V37330 \\
Elipar S10 & & LED & 3M ESPE, St Paul, MN, USA & $939112-01277$ \\
Bluephase G2 & LED & Ivoclar Vivadent, Amherst, NY, USA & P634762 S607644 \\
\hline
\end{tabular}


specimen in 10 seconds could be determined, the area under the power-vs-time graph was calculated.

\section{Specimen Fabrication}

The Filtek Supreme Ultra RBC was expressed and packed into a $2.0-\mathrm{mm}$ thick metal ring, whereas the Tetric EvoCeram Bulk Fill was expressed into both 2.0 and 4.0-mm thick metal rings (Fig. 1). Both rings had a 4.0-mm internal diameter that matched the mold diameter as specified in the ISO 4049 standard and the $4.0 \mathrm{~mm}$ aperture into the integrating sphere. The RBC specimens were centered on the diamond element of a horizontal attenuated total reflectance (ATR) attachment (Golden Gate, SPECAC, Inc., Smyrna, GA) in a Fourier transform mid-infrared (FTIR) spectrophotometer (Bruker Optics Inc., Billerica, MA). The top surfaces of the uncured samples were covered by a Mylar strip to avoid contact with the curing light tip. Each RBC sample was exposed to light for 10 seconds using the Valo in the standard curing mode.

\section{Degree of Conversion and Knoop Microhardness Measurements}

The DC was collected in real time for 120 seconds at two different temperatures, $23^{\circ} \mathrm{C}$ and $33^{\circ} \mathrm{C}$, on the ATR plate (Fig. 2). The spectrometer data collection rate was 8.4 measurements per second. Data were collected for 10 seconds before the LCU was switched on to determine the DC baseline of the uncured RBC, and for 110 seconds thereafter.

The RBC specimens were irradiated for 10 seconds according to the digital timer of the LCU. After the DC at the bottom had been collected for 120 seconds, the specimen was removed and placed immediately on a Knoop microhardness testing device (HM 123; Mitutoyo Canada Inc., Mississauga, ON, Canada).

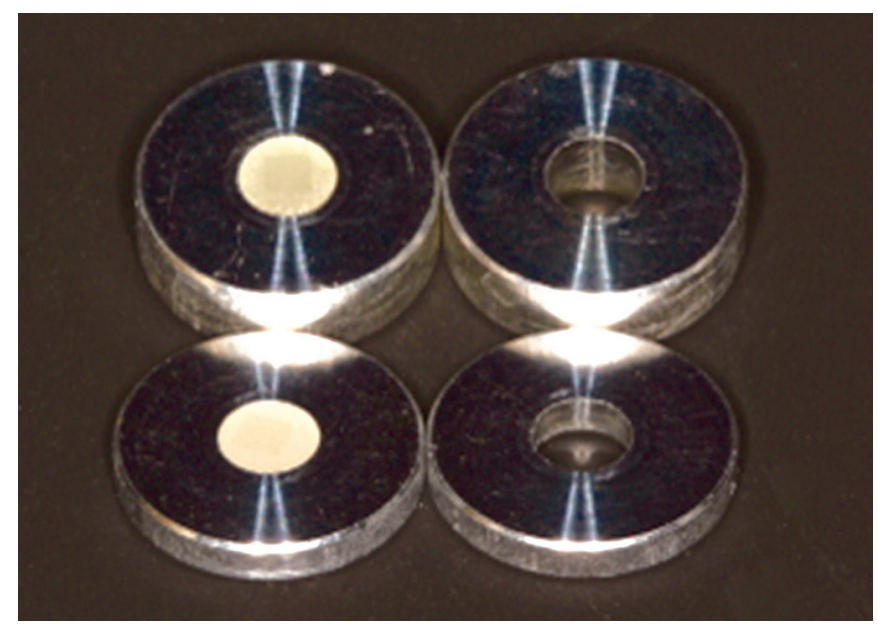

Fig. 1: Metal rings with and without cured RBC. Rings were 2 or $4 \mathrm{~mm}$ thick with an internal diameter of $4 \mathrm{~mm}$
The microhardness was measured as soon as physically possible (within 5 minutes for bottom and within 15 minutes on top surfaces) at nine points, first across the bottom surface within the region where the DC measurements were made and then at nine points across the top surfaces of each specimen.

\section{Evaluation of the Test Results}

Five specimens were made for each condition. After the hardness measurements were made, the specimens were stored in distilled water in complete darkness at $37^{\circ} \mathrm{C}$. Knoop hardnesses were retested 24 hours later and again 7 days after the samples were made. The mean bottom $\mathrm{KHN}$ and mean top KHN values were compared to determine the bottom:top hardness ratio.

The effects of the different temperatures on the DC and immediate KHN values, and the effects of 24-hour and 7-day storage on $\mathrm{KHN}$, were compared by three-way analysis of variance (ANOVA) and Fisher's protected least significant difference (PLSD) post hoc multiple comparison tests $(\mathrm{p}<0.05)$.

\section{RESULTS}

Based on the power-vs-time data, the RBC specimens received a mean irradiance of $1450 \mathrm{~mW} / \mathrm{cm}^{2}$ for 10 seconds and a radiant exposure of $14.5 \mathrm{~J} / \mathrm{cm}^{2}$ (Graph 1 ).

The DC values for the specimens cured at $23^{\circ} \mathrm{C}$ were lower than those for specimens cured at $33^{\circ} \mathrm{C}$ (Graph 2 This was shown for both RBC types tested at different depths.

The KHN was also lower for the specimens cured at $23^{\circ} \mathrm{C}$ than those cured at $33^{\circ} \mathrm{C}(\mathrm{p}<0.05)$. The KHN increased significantly at 24 hours but not at 7 days [except for the bottom surface of TBF $4 \mathrm{~mm}$ at $23^{\circ} \mathrm{C}$ ) $(\mathrm{p}<0.05)$ ] (Tables 2 and 3). For the TBF2, KHN value increased by $26.1 \%$ between curing at $23^{\circ} \mathrm{C}$ and $33^{\circ} \mathrm{C}$

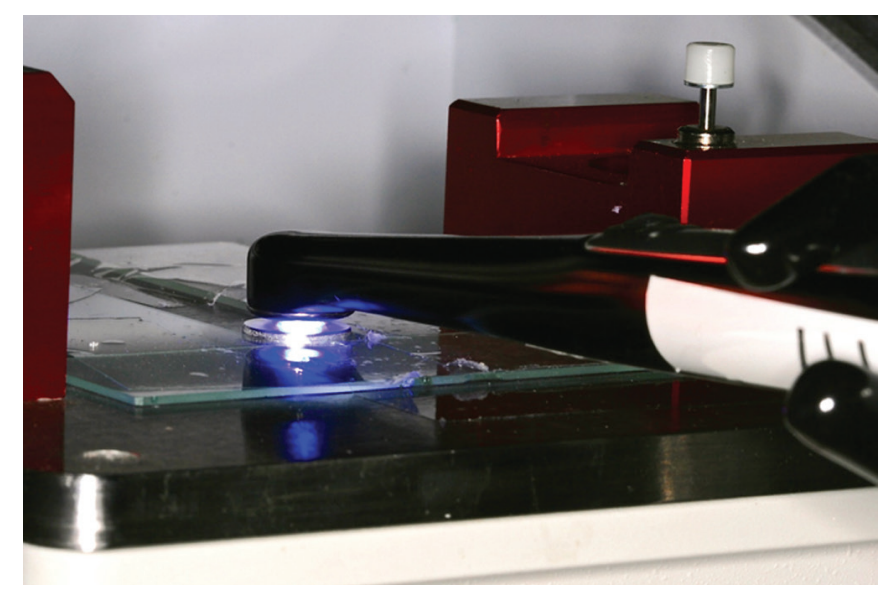

Fig. 2: Valo LED fixed above RBC during light curing. Note that the metal ring (with cured resin) is centered on the diamond element of the heated ATR attachment in an FTIR spectrophotometer 


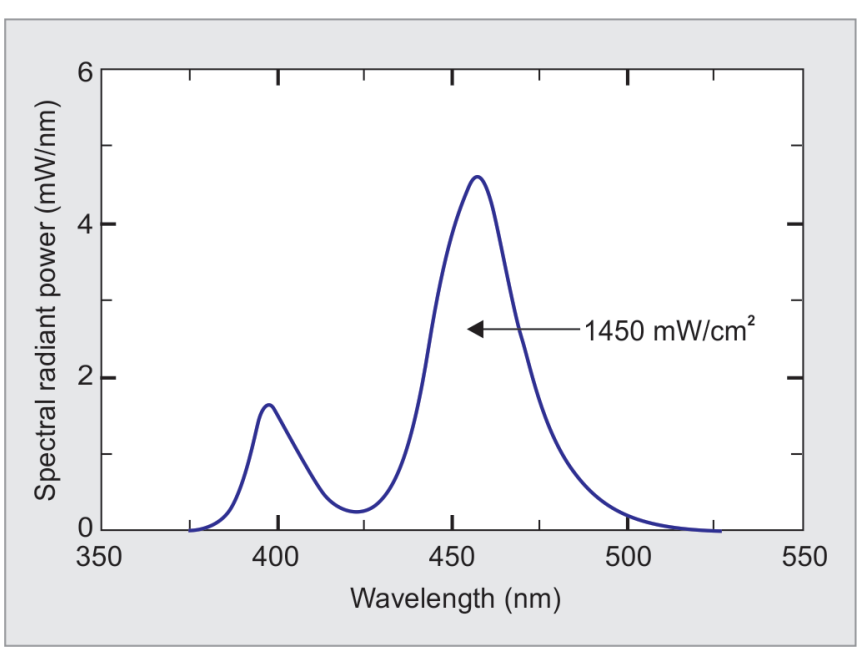

Graph 1: Spectral emission from the Valo measured through a 4-mm aperture into an integrating sphere, showing two distinct emission peaks

13.8-17.4), whereas for the same thickness, FS showed a $35.8 \%$ increase (21.2-28.8). The TBF4 samples showed a highly significant increase of $79.5 \%$ (7.5-13.5). At the top of the samples, TBF2 had an $8.4 \%$ increase, and FS had an $18.2 \%$ increase, but TBF4 showed the greatest increase in KHN (27.3\%) (Graph 3).

The bottom:top hardness ratio for all samples cured at $33^{\circ} \mathrm{C}$ was greater than that for samples cured at $23^{\circ} \mathrm{C}$. For example, at a temperature of $23^{\circ} \mathrm{C}, \mathrm{TBF} 2$ had $62.6 \%$, $\mathrm{FS} 2$ had $69.4 \%$, and TBF4 was only $36.4 \%$, but at $33^{\circ} \mathrm{C}$, samples of TBF2, FS, and TBF4 were $72.8,79.6$, and $51.3 \%$ respectively.

\section{DISCUSSION}

Previous studies have reported that higher temperatures from $40^{\circ} \mathrm{C}$ to $60^{\circ} \mathrm{C}$ will have a strong and positive influence on the polymerization kinetics of a dental restorative composite. ${ }^{9,14}$ This study showed that a lower

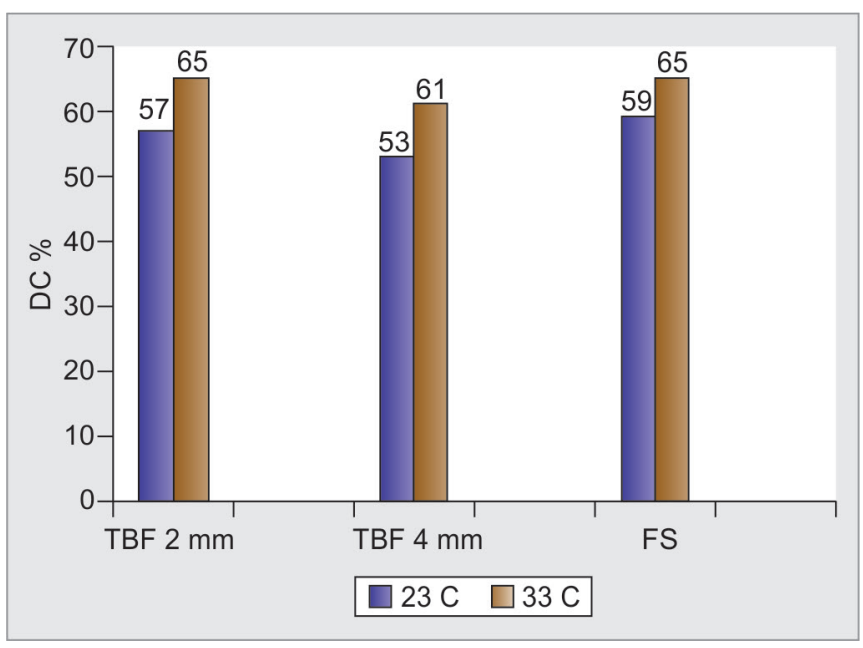

Graph 2: Degree of conversion of RBCs at temperatures of $23^{\circ} \mathrm{C}$ and $33^{\circ} \mathrm{C}$

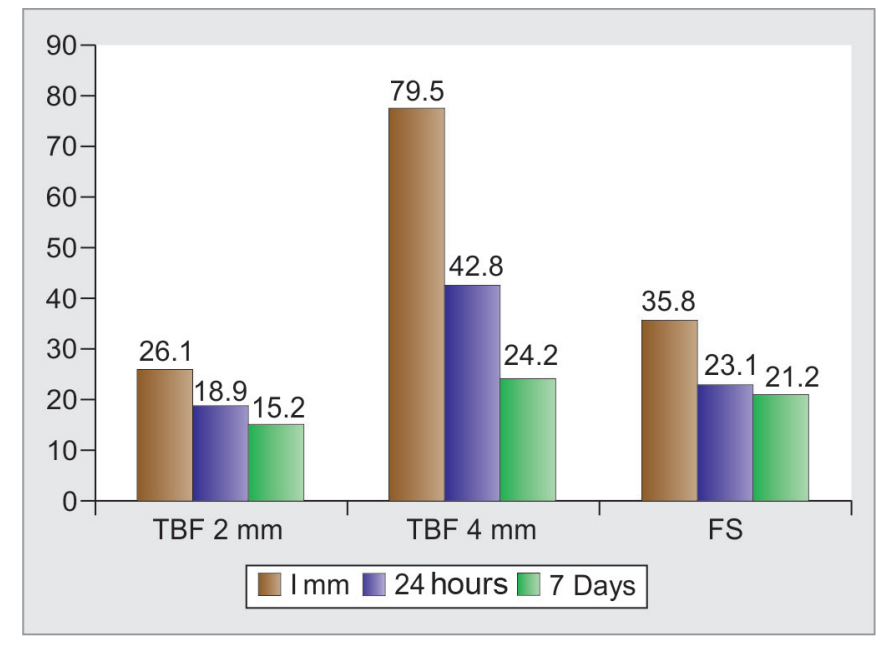

Graph 3: Differences in percentages for immediate, 24-hour, and 7-day $\mathrm{KHN}$ values for the three RBCs at temperatures of $23^{\circ} \mathrm{C}$ and $33^{\circ} \mathrm{C}$

Table 2: Means and standard deviations ( \pm SD) $[$ top $(T)$ and bottom (B)] for immediate and delayed (24 hrs and 7 days) KHN for RBCs, Tetric EvoCeram Bulk Fill, $2 \mathrm{~mm}$ (TBF2) and $4 \mathrm{~mm}$ (TBF4) thick, and Filtek Supreme Ultra, $2 \mathrm{~mm}$ thick (FS) at $23^{\circ} \mathrm{C}$

\begin{tabular}{|c|c|c|c|c|c|c|}
\hline \multirow[b]{3}{*}{ Time } & \multicolumn{6}{|c|}{$23^{\circ} \mathrm{C}$} \\
\hline & \multicolumn{2}{|c|}{ TBF2 } & \multicolumn{2}{|c|}{ TBF4 } & \multicolumn{2}{|c|}{ FS } \\
\hline & $T$ & $B$ & $T$ & $B$ & $T$ & $B$ \\
\hline Immediate & $22.04(0.50)$ & $13.80(1.37)$ & $20.66(0.81)$ & $7.52(0.50)$ & $30.62(1.20)$ & $21.24(1.05)$ \\
\hline $24 \mathrm{hrs}$ & $25.14(1.14)$ & $16.38(0.43)$ & $24.92(0.61)$ & $10.50(0.83)$ & $35.30(1.20)$ & $25.12(0.86)$ \\
\hline 7 days & $25.12(0.62)$ & $17.12(1.62)$ & $25.10(0.84)$ & $12.36(0.27)$ & $35.34(1.62)$ & $26.46(0.53)$ \\
\hline
\end{tabular}

Table 3: Means and standard deviations ( \pm SD) [top ( $T$ ) and bottom (B)] for immediate and delayed (24 hrs and 7 days) KHN for RBCs, Tetric EvoCeram Bulk Fill, $2 \mathrm{~mm}$ (TBF2) and $4 \mathrm{~mm}$ (TBF4) thick, and Filtek Supreme Ultra, $2 \mathrm{~mm}$ thick (FS) at $33^{\circ} \mathrm{C}$

\begin{tabular}{|c|c|c|c|c|c|c|}
\hline \multirow[b]{3}{*}{ Time } & \multicolumn{6}{|c|}{$33^{\circ} \mathrm{C}$} \\
\hline & \multicolumn{2}{|c|}{ TBF2 } & \multicolumn{2}{|c|}{ TBF4 } & \multicolumn{2}{|c|}{ FS } \\
\hline & $T$ & $B$ & $T$ & $B$ & $T$ & $B$ \\
\hline Immediate & $23.9(0.77)$ & $17.4(0.95)$ & $26.3(1.42)$ & $13.5(0.94)$ & $36.2(1.66)$ & $28.8(1.36)$ \\
\hline $24 \mathrm{hrs}$ & $26.3(0.59)$ & $19.5(0.74)$ & $28.4(1.16)$ & $14.9(0.72)$ & $38.2(0.96)$ & $30.9(1.10)$ \\
\hline 7 days & $26.8(0.55)$ & $19.7(1.0)$ & $28.8(1.75)$ & $15.4(1.29)$ & $38.5(0.65)$ & $32.0(1.40)$ \\
\hline
\end{tabular}


and more clinically relevant temperature also has a highly significant effect on the DC and KHN values of both conventional and bulkfill RBCs. Thus, the first hypothesis was rejected. This effect could be seen in the immediate, 24-hour, and 7-day samples. Thus, the second hypothesis was rejected. There was also a significant difference between the results from the 2 and 4-mm thick specimens of RBCs; thus, the third hypothesis was rejected.

Many studies, including the ISO standard, have investigated the properties of RBCs at room temperature $\left(20^{\circ} \mathrm{C}-\right.$ $\left.24^{\circ} \mathrm{C}\right) .{ }^{8,16,17}$ However, the value of such tests when these RBCs are at a higher temperature (i.e., in the mouth) must now be questioned. This study showed that higher DC and $\mathrm{KHN}$ values were reached on all the surfaces of specimens tested when cured at $33^{\circ} \mathrm{C}$. This occurs because, at higher temperatures, there is an increased molecular mobility, leading to an increase in monomer conversion. ${ }^{8,14}$ As the temperature increases, the diffusion-controlled propagation, the reaction diffusion controlled termination, and the autodeceleration phases are delayed, thereby allowing the RBCs to reach higher DC values before vitrification. As a result, a more highly crosslinked polymer network with improved mechanical and physical properties is produced at higher temperatures. This effect is more pronounced as the thickness of the RBC increases. 9,18,19

For any RBC to be approved for commercial use, its mechanical properties (e.g., microhardness) must be evaluated. Testing protocols for dental resin materials involve ISO standard $4049 .^{20}$ To comply with ISO test methods, the RBCs used in this study were prepared in a metal mold with an internal diameter of $4.0 \mathrm{~mm}$, the DC was measured during curing, and the $\mathrm{KHN}$ was tested soon after light-curing was completed.

Our findings showed lower bottom:top hardness ratio percentages when compared with others reported in the literature. ${ }^{21-23}$ Although specimens involved in this study received energy of $14.5 \mathrm{~J} / \mathrm{cm}^{2}$, our immediate values were in the range of $\mathrm{KHN} 36.4$ to 69.4 and a bottom:top hardness ratio of 51.3 to $79.6 \%$ when cured at $23^{\circ} \mathrm{C}$ and $33^{\circ} \mathrm{C}$ respectively. Some previous studies reported in the literature have used a 6 or $8-\mathrm{mm}$ diameter mold when testing dental materials. A recent study by Erickson et $\mathrm{al}^{24}$ examined the effects of different mold diameters on the DC of one RBC. They tested the effects of using molds that were $3,4,5$, and $6 \mathrm{~mm}$ in diameter and found that as the diameter decreased, the DC also decreased. This occurred because the relative absorption of the curing light by the walls of the mold was greater as the volume of the RBC was reduced. Thus, less light energy reached the bottom of the RBC, and the DC was lower at the bottom. ${ }^{24,25}$ These previous findings, together with others reported in the literature, ${ }^{26,27}$ could explain why this experiment showed lower values regarding bottom hardness values for the RBC samples in this study.
The effect of time on the RBCs was the same for all specimens. All had an increased KHN after 24 hours compared with their immediate values (Tables 2 and 3). At the top surfaces of the samples cured at $23^{\circ} \mathrm{C}$, there was a similar small increase after 24 hours of storage that ranged between 14.1 and $20.6 \%$ for both RBCs. The bottom surface showed a greater increase. The increase in TBF2 and FS was 18.7 and $18.3 \%$ respectively, but for $\mathrm{TBF} 4$, the increase jumped to $39.6 \%$. In contrast, all the samples cured at $33^{\circ} \mathrm{C}$ had a similar percentage of increase. At the top surface, there was a small increase of $10,5.5$, and $8.6 \%$ for TBF2, FS2, and TBF4 respectively. At the bottom surface, there was a similar small increase that ranged between 7.3 and $12.1 \%$.

In comparisons of $\mathrm{KHN}$ values after 24 hours for samples cured at $23^{\circ} \mathrm{C}$ and $33^{\circ} \mathrm{C}$, there was a clear difference. At the top surfaces, the KHN for TBF2 and FS showed a small increase of 4.6 and $8.2 \%$, but TBF4 had a larger increase of $14 \%$. The KHN values at the bottom surface also increased. The largest increase was seen in the TBF4 (41.9\%). The TFB2 and FS had similar smaller increases of 19 and $23 \%$ respectively. This effect continued in the same pattern when the samples were analyzed after 7 days of storage. At the top surface, the increase in KHN values ranged between 6.7 and 14.7\% [6.7 (TBF2), 8.9 (FS), 14.7 (TBF4)]. For the bottom surfaces, the percentage ranged between 15.1 and $24.6 \%$. These results suggest that temperature has a greater effect when the RBC is less well-cured, that is, has a lower DC, and supports previous findings reported by Daronch et al. ${ }^{9}$ The results also showed that even after 7 days, the samples cured at $33^{\circ} \mathrm{C}$ still had higher values in both top and bottom surfaces.

In this study, the correlation between DC and KHN was also evaluated. After DC measurements were collected, the study protocol minimized the time difference between when the DC and the KHN values at the bottom were recorded. There was a good linear correlation between $\mathrm{DC}$ and $\mathrm{KHN}$ at both temperatures $\left[\mathrm{R}^{2}=0.86\left(23^{\circ} \mathrm{C}\right)\right.$ and $\left.\mathrm{R}^{2}=0.82\left(33^{\circ} \mathrm{C}\right)\right]$. This is in contrast to studies that reported a weaker correlation. The better correlation probably occurred because of the minimal time difference between the DC and the KHN measurements, and the RBCs were not polished. Polishing the specimen would have taken time and may create a harder and better cured surface due to heat generation.

This study showed that testing RBCs according to the ISO 4049 standard likely simulates the "worst case scenario." Due to the lower bottom KHN values found in this study, and to rule out any potential issues because the Valo curing unit was used, the LCU from the manufacturer of the RBC materials was also used to prepare a few specimens of RBC for comparison. An 
Elipar S10 (3M ESPE, St Paul, MN) was used to cure FS, and the Bluephase G2 (Ivoclar Vivadent, Amherst, NY) was used to cure TBF. Each sample was cured at $33^{\circ} \mathrm{C}$ (total of three samples for each FS, TBF2, and TBF4). The results showed that when these RBCs were cured in 4-mm diameter metal molds for 10 seconds, comparable results were obtained. These lights were used for 60 seconds, when they produced higher bottom KHN values (with a bottom/top ratio of 86 to $90.5 \%$ ).

This study used only two RBCs, but in light of results reported from other studies, it is probable that other RBCs will also achieve greater DC and KHN values when tested at simulated intraoral temperatures. A better mold design would be one that simulated the light and thermal properties found in the tooth.

\section{CONCLUSION}

Within the limitations of this study, it could be concluded that

- Small differences between room and intraoral temperatures had a significant effect on the DC and KHN of the tested RBCs $(\mathrm{p}<0.05)$.

- Cavities with a low volume and a high surface area ratio may need longer light exposure times to ensure an adequate cure at the bottom surfaces.

- Physical properties of the RBC should be tested both immediately and 24 hours after RBC placement, to determine whether there is any increase in the physical properties of the material.

\section{Clinical Relevance}

Clinician should look for studies conducted at mouth temperatures, look into reports immediate and 24-hour results. Degree of conversion and $\mathrm{KHN}$ values recorded at intraoral temp will be better and the immediate results will be lower.

\section{ACKNOWLEDGMENT}

The author thanks Professor Richard B Price for his valuable guidance.

\section{REFERENCES}

1. Lynch CD, Opdam NJ, Hickel R, Brunton PA, Gurgan S, Kakaboura A, Shearer AC, Vanherle G, Wilson NH. Guidance on posterior resin composites: Academy of Operative Dentistry-European Section. J Dent 2014 Apr;42(4): 377-383.

2. Rueggeberg FA, Caughman WF, Curtis JW, Jr. Effect of light intensity and exposure duration on cure of resin composite. Oper Dent 1994 Jan-Feb;19(1):26-32.

3. Czasch P, Ilie N. In vitro comparison of mechanical properties and degree of cure of bulk fill composites. Clin Oral Investig 2013 Jan;17(1):227-235.
4. Scotti N, Venturello A, Migliaretti G, Pera F, Pasqualini D, Geobaldo F, Berutti E. New-generation curing units and short irradiation time: the degree of conversion of microhybrid composite resin. Quintessence Int 2011 Sep;42(8): e89-e95.

5. Santini A, Miletic V, Swift MD, Bradley M. Degree of conversion and microhardness of TPO-containing resin-based composites cured by polywave and monowave LED units. J Dent 2012 Jul;40(7):577-584.

6. Rueggeberg FA. State-of-the-art: dental photocuring-a review. Dent Mater 2011 Jan;27(1):39-52.

7. Oberholzer TG, Makofane ME, du Preez IC, George R. Modern high powered led curing lights and their effect on pulp chamber temperature of bulk and incrementally cured composite resin. Eur J Prosthodont Restor Dent 2012 Jun;20(2):50-55.

8. Palin WM, Hadis MA, Leprince JG, Leloup G, Boland L, Fleming GJ, Krastl G, Watts DC. Reduced polymerization stress of MAPO-containing resin composites with increased curing speed, degree of conversion and mechanical properties. Dent Mater 2014 May;30(5):507-516.

9. Daronch M, Rueggeberg FA, De Goes MF, Giudici R. Polymerization kinetics of pre-heated composite. J Dent Res 2006 Jan;85(1):38-43.

10. Lovell LG, Newman SM, Bowman CN. The effects of light intensity, temperature, and comonomer composition on the polymerization behavior of dimethacrylate dental resins. J Dent Res 1999 Aug;78(8):1469-1476.

11. Trujillo M, Newman SM, Stansbury JW. Use of near-IR to monitor the influence of external heating on dental composite photopolymerization. Dent Mater 2004 Oct;20(8): 766-777.

12. Elhejazi AA. The effects of temperature and light intensity on the polymerization shrinkage of light-cured composite filling materials. J Contemp Dent Pract 2006 Jul 1;7(3):12-21.

13. Atai M, Watts DC. A new kinetic model for the photopolymerization shrinkage-strain of dental composites and resinmonomers. Dent Mater 2006 Aug;22(8):785-791.

14. Watts DC, Alnazzawi A. Temperature-dependent polymerization shrinkage stress kinetics of resin-composites. Dent Mater 2014 Jun;30(6):654-660.

15. Price RB, Whalen JM, Price TB, Felix CM, Fahey J. The effect of specimen temperature on the polymerization of a resincomposite. Dent Mater 2011 Oct;27(10):983-989.

16. Hadis M, Leprince JG, Shortall AC, Devaux J, Leloup G, Palin WM. High irradiance curing and anomalies of exposure reciprocity law in resin-based materials. J Dent 2011 Aug;39(8):549-557.

17. Schneider LF, Consani S, Ogliari F, Correr AB, Sobrinho LC, Sinhoreti MA. Effect of time and polymerization cycle on the degree of conversion of a resin composite. Oper Dent 2006 Jul-Aug;31(4):489-495.

18. Giorgi MC, Lima DA, Marchi GM, Ambrosano GM, Aguiar $\mathrm{FH}$. Influence of softening test and light-activation protocols on resin composite polymer structure. Eur J Dent 2014 Jan;8(1):9-14.

19. Daronch M, Rueggeberg FA, De Goes MF. Monomer conversion of pre-heated composite. J Dent Res 2005 Jul;84(7):663-667.

20. Hofmann N, Hugo B, Klaiber B. Effect of irradiation type (LED or QTH) on photo-activated composite shrinkage strain kinetics, temperature rise, and hardness. Eur J Oral Sci 2002 Dec;110(6):471-479. 
21. Ozcan S, Yikilgan I, Uctasli MB, Bala O, Kurklu ZG. Comparison of time-dependent changes in the surface hardness of different composite resins. Eur J Dent 2013 Sep;7(Suppl 1):S20-S25.

22. Moore BK, Platt JA, Borges G, Chu TM, Katsilieri I. Depth of cure of dental resin composites: ISO 4049 depth and microhardness of types of materials and shades. Oper Dent 2008 Jul-Aug;33(4):408-412.

23. Price RB, Felix CA, Andreou P. Knoop hardness of ten resin composites irradiated with high-power LED and quartz-tungsten-halogen lights. Biomaterials 2005 May;26(15):2631-2641.

24. Erickson RL, Barkmeier WW. Curing characteristics of a composite. part 2: the effect of curing configuration on depth and distribution of cure. Dent Mater 2014 Jun;30(6): e134-e145.

25. Erickson RL, Barkmeier WW, Halvorson RH. Curing characteristics of a composite-part 1: cure depth relationship to conversion, hardness and radiant exposure. Dent Mater 2014 Jun;30(6):e125-e133.

26. Harrington E, Wilson HJ. Depth of cure of radiation-activated materials-effect of mould material and cavity size. J Dent 1993 Oct;21(5):305-311.

27. Asmussen E, Peutzfeldt A. Influence of specimen diameter on the relationship between subsurface depth and hardness of a light-cured resin composite. Eur J Oral Sci 2003 Dec;111(6):543-546. 